\title{
China searches for best medicine for ailing scientific journals
}

\author{
$\longrightarrow$ \\ hina's scientific journals are, \\ simply put, plagued by medi- \\ ocrity.
}

The country has over 5000 mostly Chinese-language science and technology journals, but many of the articles they publish are unread and rarely cited.

For good reason, says Sun Jianzhong, a doctor in Qingtian People's Hospital in the southeastern province of Zhejiang. "Many Chinese scientific journals are neither scrupulous nor scientific. Articles published in these journals are not intended to impact or influence scientific research. They are used for the sake of promoting one's career."

Sun's opinion is far from rare.

In fact, even the Chinese government acknowledges that a measure of quality control needs to be introduced and to that end, it has announced that it will severely whittle down the number of journals published in the country and implement a measure of quality control. But some say it will take more than that to revitalize Chinese journals to the point where its own academics and foreign researchers might submit blue-chip papers.

Many Chinese journals are now driven by a dynamic in which many grad students and professors, under pressure to publish, churn out unoriginal, lowquality papers. Some even turn to a burgeoning black market of ghostwriters and illegitimate journals - an industry worth one billion Chinese Yuan in 2009, or about $\$ 151$ million, (Joint Conference on Digital Libraries 2009; 443-44).

So endemic is the misconduct that Zhang Yuehong, managing editor of the Journal of Zhejiang UniversityScience recently told Nature that 31\% of submitted papers included plagiarized content.

The Chinese government recently stepped into the fray, announcing that as of January 2011, new regulations will be rolled out to "terminate" weak journals. Li Dongdong, a vice-minister of state and deputy director at the Gen-

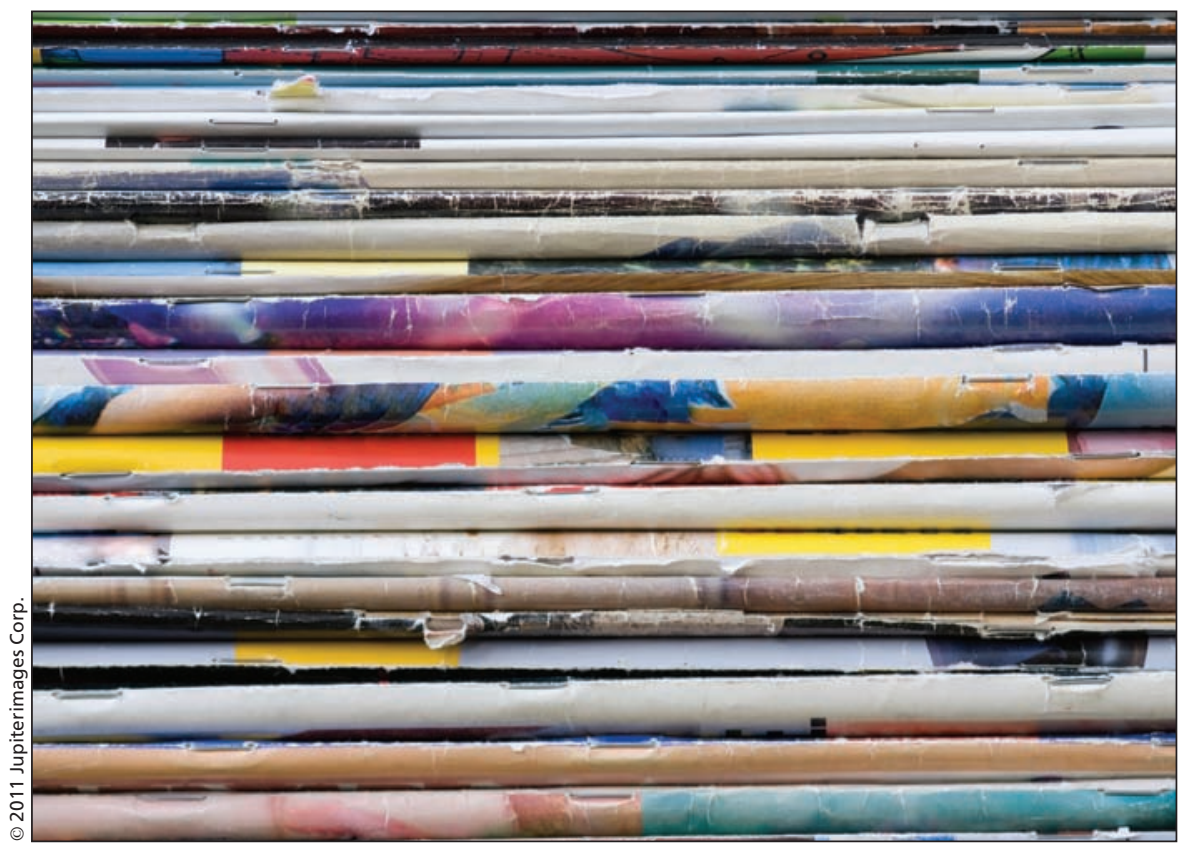

China produces over 5000 mostly Chinese-language science and technology journals, but many an article is unread and rarely cited.

eral Administration of Press and Publications, a powerful government agency responsible for regulating and distributing news in China, said in a September address that the scientific publishing industry needed major reform because of "a large gap between quality and quantity."

Under the new regulations, scientific publishing will be concentrated in " 5 to 10 large publishing groups" that will compete with each other, Li stated.

Higher standards will be used to assess the quality of submissions, while tax breaks will go to journals deemed to be strong, and increased penalties will be slapped on those producing fraudulent work. But the agency declined to discuss further details.

Ironically, the overhaul is coming at a time when Chinese science appears to be burgeoning and attracting ever more international attention. That's in part because the Chinese government has adopted policies that encourage and reward publication in major international journals, particularly ones that are included on the Science Citation Index, which covers more than 6500 significant journals across 150 disciplines.

Universities and research institutes now offer financial rewards to scientists who publish in Index-listed journals and as a consequence, China has tripled the number of papers published in leading international journals between 1999 and 2009, according to a press release from Nature China (www.naturechina.com.cn/nchina/press _releases/20090624_double_impact_en g.pdf). According to China's Institute of Science and Technology Information, the country's researchers have published 95500 papers in international journals and in 2008, accounted for $6.6 \%$ of world share, behind the United States, Britain and Germany (www.istic.ac.cn/EducationDetail.aspx ?ArticleID=88101).

Where does the race to publish abroad leave Chinese journals?

"At this point, few Western academics are likely to publish in Chinese English journals so it is difficult for 
these journals to become truly international, making it difficult for them to increase their impact factor," says Paul Weldon, former English language editor for the Journal of China University of Geosciences in Wuhan.

"Few Western academics have heard of many of the journals, even those published by the large publishers, so readership is low and citations lower," he says. "There is, therefore, little incentive to publish in the Chinese language or in Chinese journals regardless of language - and so such journals find themselves competing at something of a disadvantage on the world stage."

More than 200 science and technology journals in China have switched to the use of the English language and more are in line to follow suit by publishing in partnership with foreign companies. Neuroscience Bulletin began publishing in English in 2006; ACTA Genetica Sinica became the Journal of Genetics and Genomics in 2007 and was included on the Science Citation Index in 2008.

In 2009, ACTA Zoologica Sinica, the second-oldest journal in China, became Current Zoology and quickly saw the proportion of papers published from non-Chinese scientists leap to $42 \%$ from $16 \%$, and in 2010 , was listed in the Science Citation Index.
Such successes, though, are rare, leading some academic experts to say that the solution lies in a consolidation of campus journals, which are often run independently and are often duplicative. Others have suggested a push toward open-platform publishing, in which authors pay a fee to have research published and made freely available on the Internet (a concept that remains foreign to many Chinese academics).

Economist David Zetland suggests the solution lies in a publishing model featuring auctions using "academic" dollars. Authors would write papers and post them for auction. Editors would then bid for the best papers using academic dollars and assign the purchases to referees (peer reviewers). After review and publication, the academic dollars would be redistributed to authors, editors and referees of cited articles as a reward for quality.

Editors would presumably, bid highest for those papers they deem strongest and most likely to be cited, thereby bringing more academic dollars to the editor's pocket for future bidding. "Since papers do not generate [academic dollar] income unless they are cited, authors have an additional incentive to write well. Since referees and editors share [academic dollars], they have incentives to improve papers rather than reject them - and to speed up the review process," wrote Zetland and Dutch economist Jens Prüfer (www.springerlink.com/content/2q802 14867370564/).

"It's a way of using the market to replace the bureaucratic process," Zetland says.

The auction market "would give everyone a fair chance to survive."

Although there is no indication that the Chinese government is considering the model, Zetland believes it could work in the country, as it is "one of the world's centres for organizing pilot projects. It is very efficient at getting things done. You start with one auction, one village, one province, and roll it across the whole country."

For its part, the government says it is motivated to make Chinese publishing an international leader.

In her September address, Li said she hopes China's scientific and technological periodical publishing industry can one day become the "vanguard of reform and development."

"We must enhance our sense of responsibility and our mission to assert the international influence of China's science and technology journals to truly become a major force in science and technology development," she said. Suzanne Ma, Hong Kong

CMAJ 2011.DOI:10.1503/cmaj.109-3736 